\title{
Online Survey About Current Use Of 3D Imaging And Its User Requirements In Cultural Heritage Institutions
}

\author{
Paper Version with Graphical Illustrations
}

\author{
Mona Hess \\ UCL Civil, Environmental and Geomatic Engineering (UCL CEGE) \\ University College London \\ London, United Kingdom \\ m.hess@ucl.ac.uk
}

\begin{abstract}
The potential of 3D images is increasingly recognized by heritage professionals for opening up new technological possibilities for digital documentation, analysis and research, exhibition display and education. Yet, currently there is no comprehensive understanding of what constitute 3D image qualities for a digital artefact, from the point of view of a heritage professional. An online survey addressed to the international heritage community gauged information about current adoption of 3D imaging technologies, priorities for 3D image quality and visions of future use. Despite a number of barriers, there is a high interest in 3D imaging technologies across heritage institutions and the museum sector.
\end{abstract}

Index Terms-user requirements, survey, 3D imaging, museums, qualitative research, heritage professional users

\section{INTRODUCTION}

To understand the current use of 3D imaging technologies and their requirements in museums and cultural heritage institutions, an online survey was addressed to the international heritage community. The number of 45 completed surveys reflects an avid interest of the international audience of heritage professionals in the topic of 3D imaging of cultural heritage.

\section{BACKGROUND}

Research towards user requirements has successfully applied qualitative research and user testing in cultural heritage studies. Data collection in these studies was either approached with qualitative evaluation or quantitative evaluation, but the two are not usually connected in the same qualitative research. An example of a web-survey for user behavior is a study about the use of the British Museum online object database [1].

User testing for requirements has been demonstrated by the 3D-Coform project using scenario based evaluation. Evidence of heritage professional requirements was collected by consultation with subject specialists and by describing user scenarios for the use of 3D digital models. A report about user requirements for $3 \mathrm{D}$ models was published with the title 'Initial version of User requirement analysis and functional specifications' [2]. Testing for a 'User-appropriate viewer for high resolution interactive engagement with $3 D$ digital cultural artefacts' was conducted by Conservation Technologies Liverpool, [3] and [4]. This survey focused on the usability and interaction with the interactive viewing software. The sample of eight participants allowed conclusions for design improvements of viewing software. User comments on 3D image quality were not discussed in the paper.

The UCL Interaction Centre has proposed the 'PRET $a$ Rapporter' qualitative research method, which guides structured reporting on user-centred evaluation studies [5]. Its application was illustrated on evaluation studies of digital library systems. The acronym stands for Purpose, Resources and Constraints, Ethics, Techniques/ methods, Rapporter (reporting on findings). This approach was adopted to plan and report on the user testing in this research.

\section{PURPOSE OF USER TESTING}

The survey aimed to gauge information about current adoption of 3D imaging technologies, priorities for 3D image quality and visions of future use.

\section{RESOURCES AND CONSTRAINTS}

No specific gender, age or specialism representation was aimed at. Some respondents left their contact address to be notified about research results, most remained anonymous. This digital survey results enable the filtering of requirement profiles for $3 \mathrm{D}$ image quality indicators per professional disciplines for future research. 


\section{ETHICS AND DATA PROTECTION}

This research is registered with UCL CEGE and UCL Legal Services. The data is anonymized and data is deposited on an external encrypted hard drive. All other digital data has been deposited in the UCL Research Data Services, for future access and collaboration

\section{TECHNIQUES AND METHODS FOR DATA COLLECTION}

The research method for user testing can be summarised as mixed quantitative and qualitative testing using rated questionnaires with free text. It was published through the Opinio online survey [6] and had 25 questions. The seven ranking categories were: not applicable/ not important/ less important/ important/ more important/ significantly more important/ extremely important. The author of this research was not present as participants answered the questions, and no artefacts in 2D or 3D images were included. The online survey was launched in June 2013 and data collection stopped in August 2013 [7]. To recruit participants the international conservation and heritage community was approached. Invitees to the e-questionnaire were: from the authors professional network; from the Museums Computer Group (JISC Email discussion lists for the UK Education and Research communities with a subscription number of 1300) [8], the invitation is still available online [9]; from the Conservation Distribution List (University of Chicago) with a reach of audience overseas. The discussion list for professionals in cultural heritage preservation has a subscription number reported as 10.000 in 2010 [10]. The invitees were also prompted to forward the survey to interested parties.

\section{REPORT OF FINDINGS}

\section{A. Response rate}

The response rate to the online survey and number of completed responses were satisfactory. From 103 personal contacts, $8 \%$ answered the survey and indicated their names. This number of responses neither includes forwarded invitations nor finished surveys and anonymous responses. 79 respondents have started the questionnaire. 45 respondents have finished the complete questionnaire. Skipping of questions was possible.

\section{B. Respondents workplace and specialism}

Firstly, participants were asked to describe their workplace, role and professional specialism or discipline. Respondents worked with a great majority at the museum and/or university, but also at national institutions or as freelance professionals. The majority of participants were either researchers or graduate students. Respondent's roles showed a majority of archaeologists and conservators. The next response group was other professionals related to heritage imaging: lecturer or teacher, project managers, engineers, 3D imaging technician and 3D graphics (Questions 1/2/3).

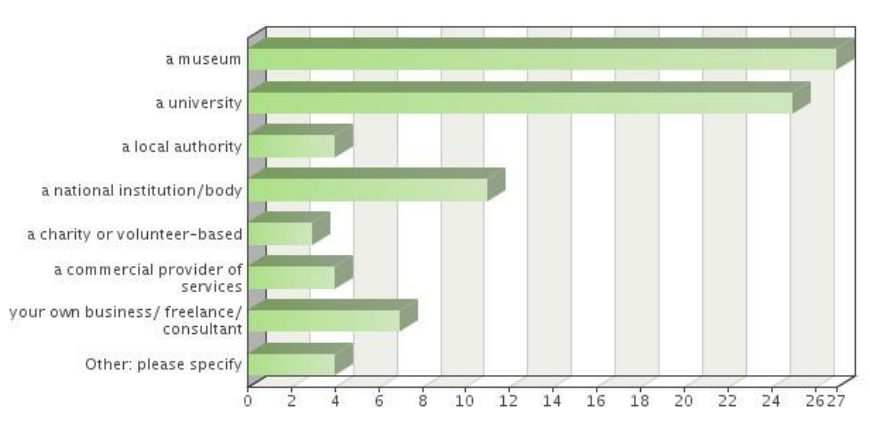

Figure 1 Where are you working (one or more answers)?

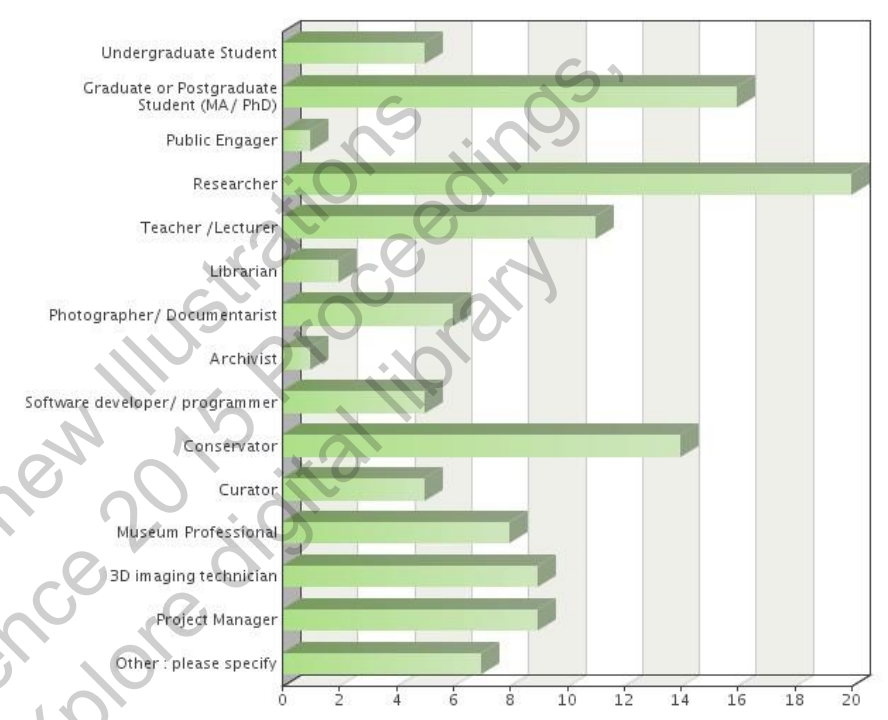

Figure 2 What is your role (one or more answers)?

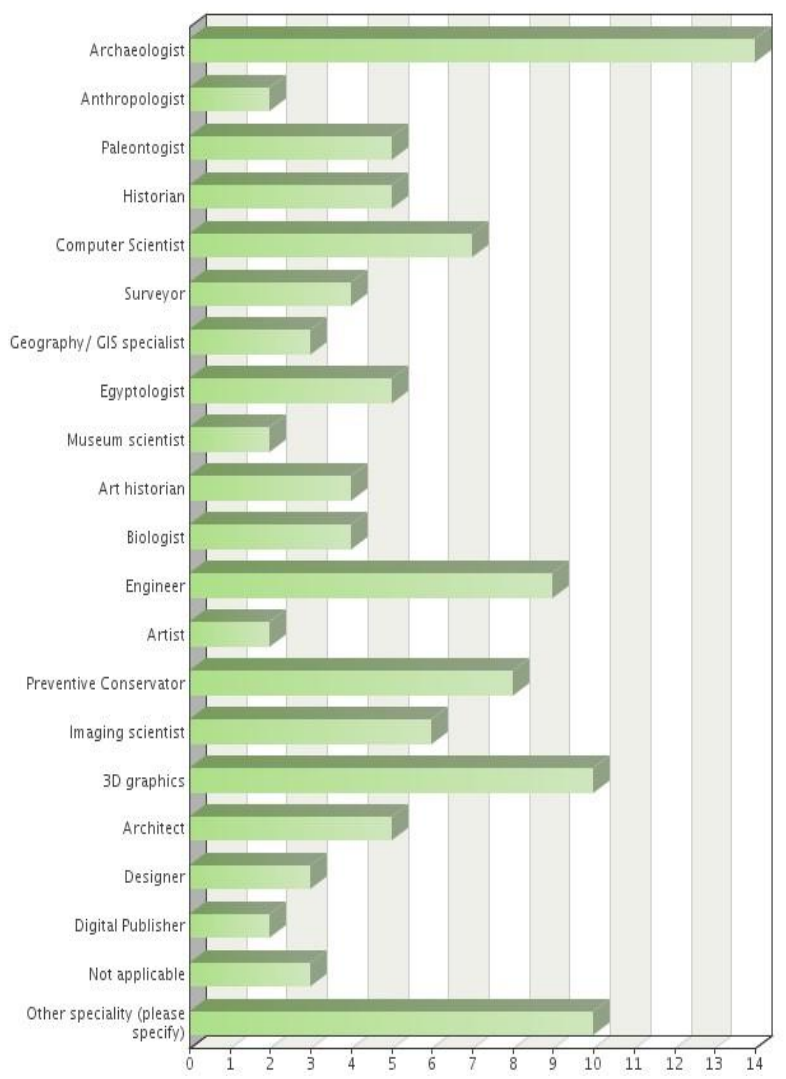

Figure 3 Describe you specialism (one or more answers) . 
About one third of online survey participants were from Europe, one third form the UK, and a smaller group of respondents were from North America. Most of the European and North American respondents are from renowned museums and heritage institutions (Question 5). The largest group of participants' are between 25 and 44 years old (Question 6), and most people confirm to have good to very good and fluent to excellent IT skills (Question 7).

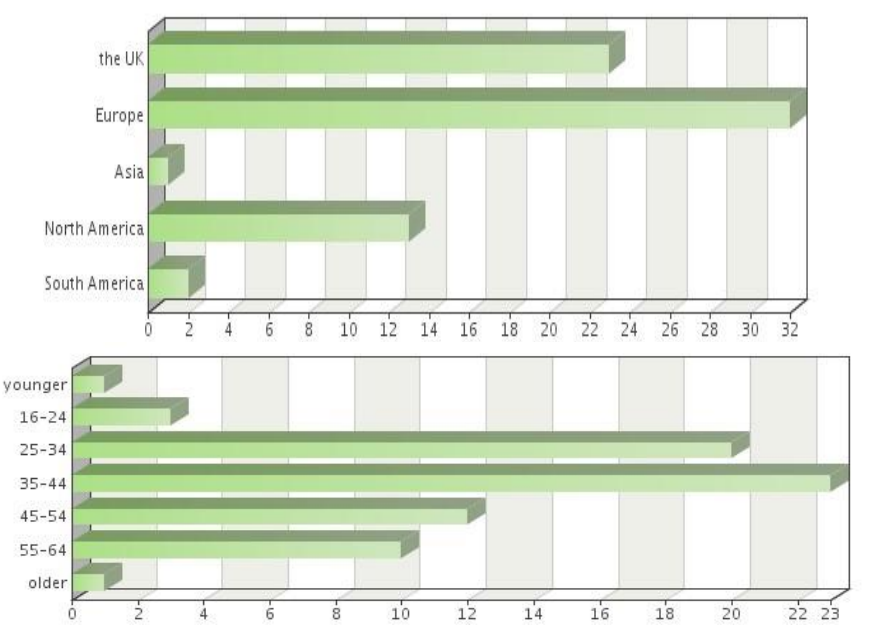

Figure 4 Where are you answering this survey? How old are you?

Most respondents have firm command of today's means of communication and technology: personal computer, digital photography and 2D image processing (all $>80 \%$, Question 8 ). More than half of the respondents are already viewing and manipulating 3D images (Question 8). About one third of all respondents are using 3D imaging in their daily work. Respondents indicated that $62 \%$ are already using 3D imaging at their workplace, and some are starting to explore the acquisition of equipment (6\%, Question 10). Therefore, it is important to ascertain what heritage professionals' motivations, aims and expectations for the use 3D digital imaging technologies are.

\section{Object size}

Participants were asked to indicate all sizes of objects that they are dealing with in their daily work. The object size with a pronounced maxima was between 1-60cm (Question 9).

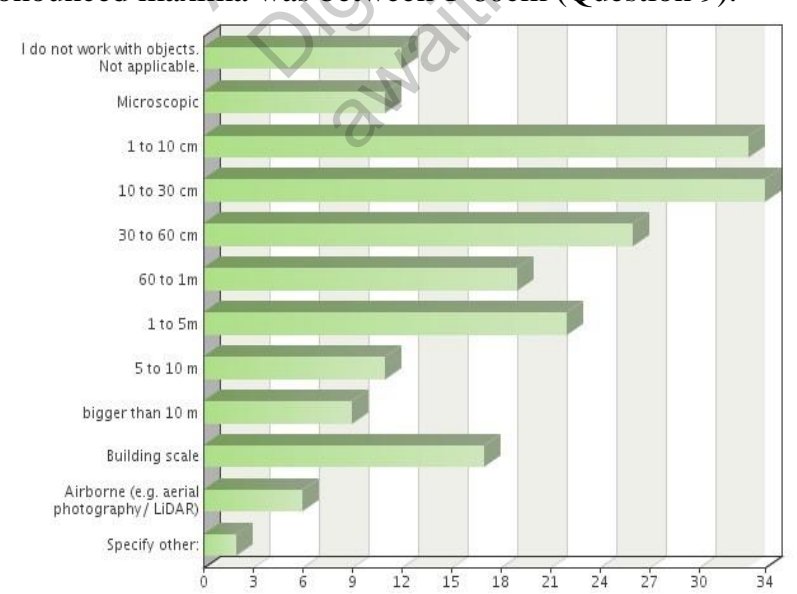

Figure 5 What is the typical object size you are working with?

\section{Technologies for digital documentation currently used in heritage institutions}

The next question is exploring, which equipment is already present in cultural heritage institutions for digital documentation including 3D. Multiple answers were encouraged (results in adjusted relative frequency in this section). While in this question covered a great number of techniques for documentation and analytical imaging are queried, this report concentrates on responses for optical imaging technologies. The majority of respondents use digital photography $(89 \%)$, followed by 2D digitized material $(56 \%)$, such as text (48\%) and drawings/illustrations (66\%) for documentation. Furthermore, 3D laser scanning close-range (33\%) and longer-range (25\%), 3D handheld scanning $(25 \%)$ alongside structured-light projection (15\%) and consumergrade 3D sensors (Kinect-type, 12\%) seem to be most dominant for object digitisation. About one third of heritage institutions use photography-based recording for digital documentation: (stereo-) photogrammetry (34\%), Structure from Motion (21\%) and PTM/RTI (25\%). Other techniques involving more specialised equipment for 3D imaging is used by more than half the respondents (64\%, Question 11). Result for use of digital documentation shows that respondents were familiar with $3 \mathrm{D}$ imaging technologies.

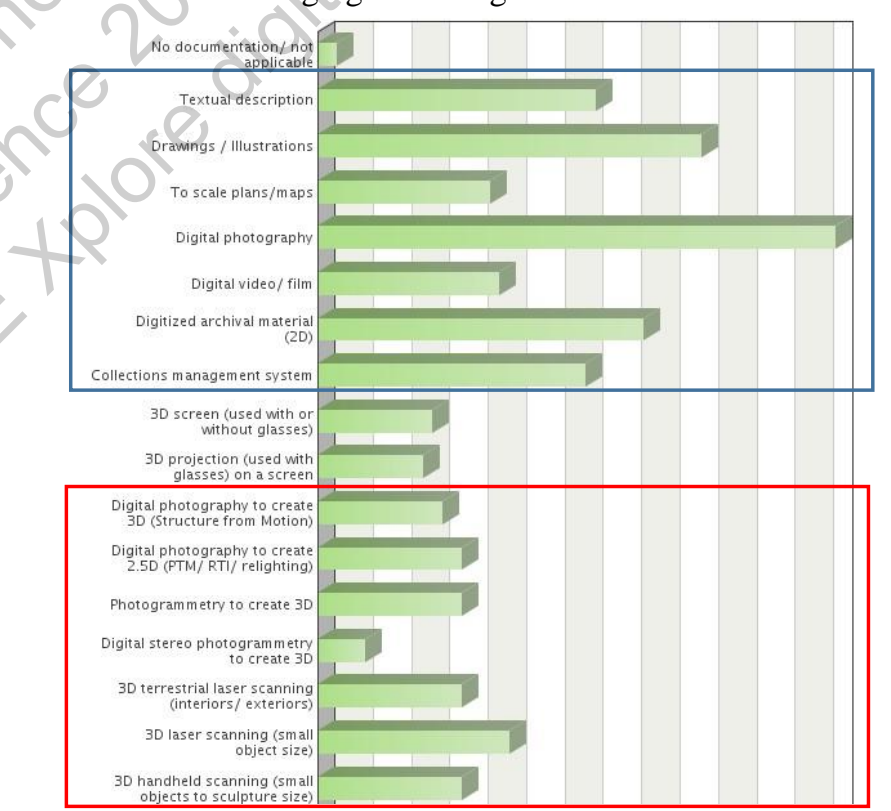

Figure 6 Technologies currently used for digital documentation in your institution / in your work? 


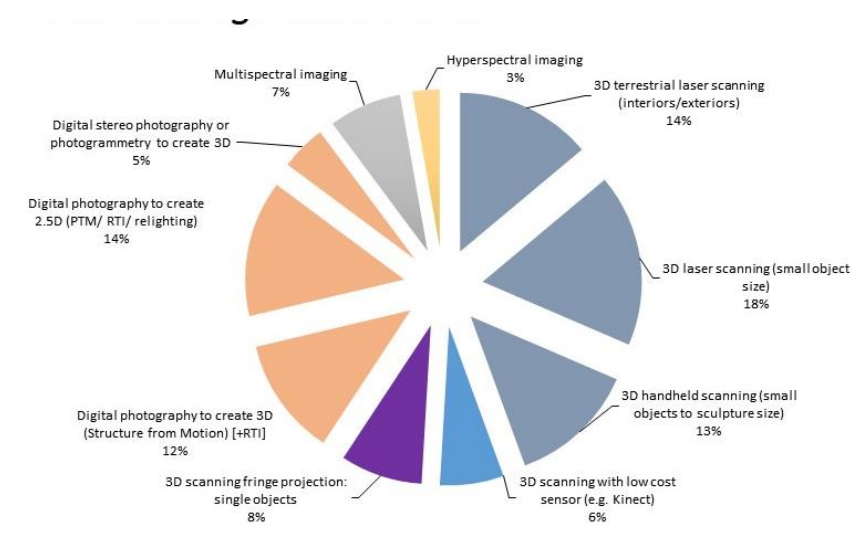

Figure 7 Technologies currently used for digital documentation in your institution / in your work? As pie chat.

\section{E. Participants' motivation for $3 D$ imaging}

The main 3D imaging motivation for heritage professionals was the production of a digital surrogate and virtual reconstruction $(71 \%$ and $52 \%)$. This outcome suggests that currently opportunities for new use of 3D technologies for visitors are recognized as opportunities to complement other documentation and research methods, with geometrically exact measurement $(57 \%)$, the response to scientific and conservation related questions $(47 \%)$. This is followed by employing these digital surrogates for outreach activities such as teaching and learning (42\%). It is suspected that users for digital surrogates see correct geometry as a given prerequisite for any type of 3D imaging. However, from an imaging metrology point of view data is very variable in quality. It can be concluded that cultural heritage professionals certainly see scope for using digital 2.5 and 3D imaging for research and documentation in the museum workflow (Question 13).

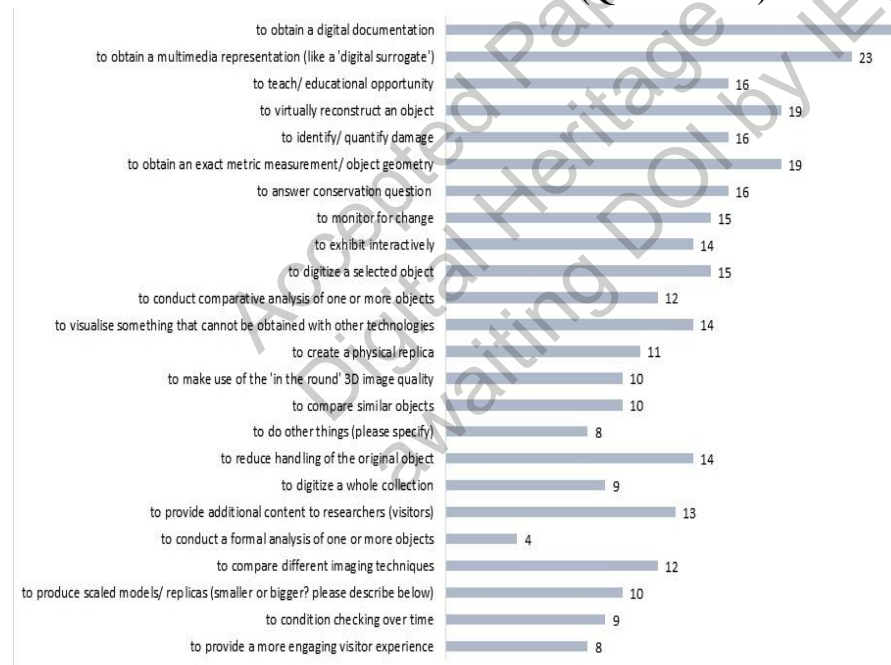

Figure 8 Respondents motivation for 3D imaging

\section{F. $3 D$ imaging requirements}

The next three questions were constructed to find out, if heritage professionals already have priorities to inform specifications for 3D imaging if they would commission 3D imaging work (Question 15).
10.MPact

DD Imaging, Metrology \& Photogramme
Applied Coordinate Technologies

When asked, if planning options for repurposing of images from the beginning of a project was relevant, more than half of the respondents found it important. This same criterion has been queried again in Question 17, for requirements after the $3 \mathrm{D}$ imaging project, where it will be as 'extremely important'. This suggests that heritage professionals should be asked to integrate 'repurposing' into their specifications at the earliest planning stage of a 3D imaging project. Respondents found most of the aspects for project planning of importance: object accessibility, clarification of terms and conditions and copyright and the ability to integrate the $3 \mathrm{D}$ imaging project with institution standards. $85 \%$ of the online respondents agreed that a clear choice of 3D imaging technologies by the respondent themselves was at least important, if not extremely important. The same response was made for creating outputs at high-resolution or to specification. About $80 \%$ of respondents also thought that time and cost employed for a 3D imaging project was important. In summary, the projection of cost and time for staff and production, and the clear choice of the fit-forpurpose imaging technology are extremely important for this group of respondents.

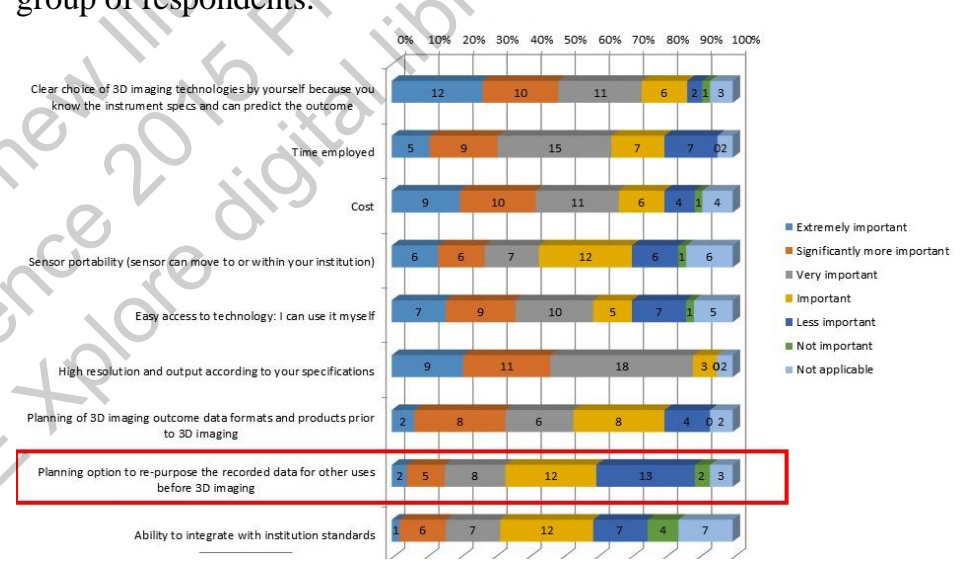

Figure $93 \mathrm{D}$ imaging requirements before a 3D imaging activity starts.

Participants were asked about the importance of a number of criteria related to the workflow during a 3D imaging project. Respondents seem to find all aspects of the ongoing 3D imaging project, from calibration of the equipment to consistency and traceability with metadata, very important. Quality control during imaging procedures and high-quality outputs are very much desired by the respondents, probably due the fact that the greater part of the respondents is already using 3D imaging in practice (63\%, Question 20). There was no clear maximum for the time of work used for processing after the acquisition, as might maybe be expected. In practice, from the authors' experience, the largest part of the time (\& cost) used to produce a model will be lying in the postprocessing (Question 15).

Respondents were asked about criteria related to the production and outcome quality after the delivery of the 3D image (Question 16). Over half of them agreed that the creation of a master dataset, scientific research on data and the possibility to re-purpose the 3D image for other uses were important as project outcomes. A consistent visual appearance (no holes) was important, but museums professionals tended find a model with holes. They acknowledged that a raw 3D scan is the 'archival dataset' that can contain holes due to 
surface complexity, and that holes represent a further step in processing with newly added data. The following three criteria were clearly the most relevant for the outcomes of a 3D imaging project, as they were ranked at least important to extremely important with $90 \%$ by respondents:

- Easy navigation and viewing without specialist software (or open source)

- The possibility to conduct accurate measurements on the $3 \mathrm{D}$ digital surrogate of the surface or the volume and for the creation of cross-sections and profiles

- And most importantly, a high-resolution output (or according to specifications).

Respondents had the opportunity to add free text with their own suggestions. Participants wrote: "easily portable to other virtual learning environments (e.g. Moodle)/ crack measurement/ monitor any changes in physical appearance of object with particular emphasis on measuring changes in the surface cracks / for use in social media / Easy navigation of the $3 D$ image without major instructions."

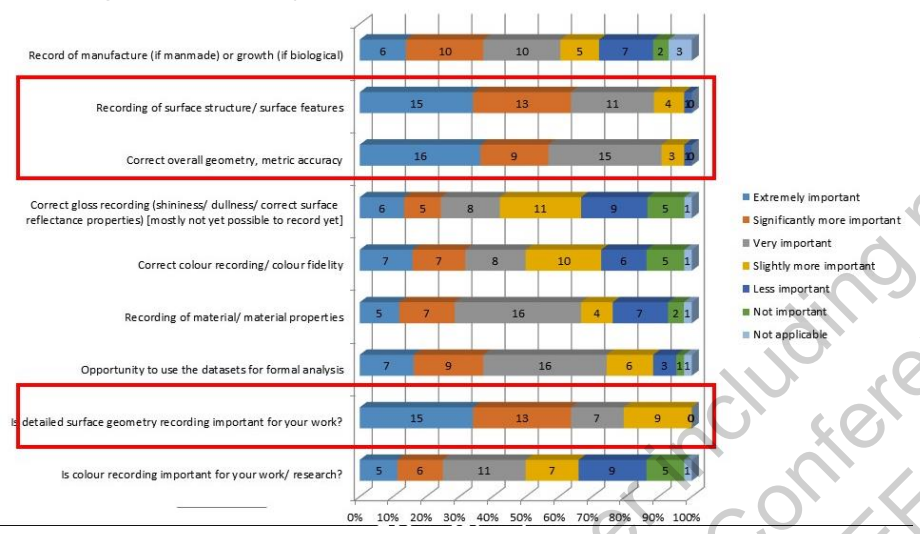

Figure $103 \mathrm{D}$ imaging requirements after a 3D imaging activity has taken place.

Participants were asked to rank a series of criteria in importance for a fit-for-purpose $3 \mathrm{D}$ image production and a high-quality 3D image outcome (Question 17).

When asked if correct overall geometry and metric accuracy, detailed surface geometry recording and recording of surface features were of importance, a resounding Yes and 'extremely important' was the prevailing answer of heritage professionals. More than half of the respondents found the opportunity to use the dataset for formal analysis important to extremely important. The understanding and concept of formal analysis varies by discipline: shape and form; in art history; colour palette and tone; anthropology: comparison of forms and patters, recurring forms and key symbols across a region. Issues related with colour the importance of colour recording for the work and correct colour recording are ranked with a maximum at important. That fact that it is not extremely important might astonish readers with conservation or colorimetry background. Respondents tended to find the ability to record material properties and gloss more important.

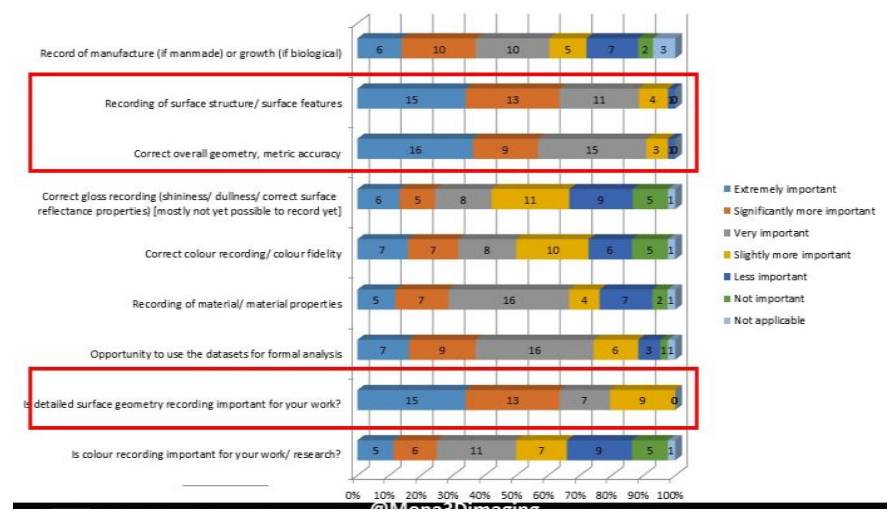

Figure 11 3D image quality criteria.

G. Barriers to the wider adoption of $3 D$ scanning by the cultural heritage sector

If 3D imaging technology is offering so many opportunities and advantages, what are the main barriers for the adoption of PTM/RTI and 3D imaging in cultural heritage and museums?

Respondents agreed that major barriers were:

- The current cost of the equipment; the cost to pay specialist technicians of provide staff training; Problems with long term data sustainability.

These answers confirm that heritage professionals are looking at a long term data preservation, and - as more immediate concern - for time and cost issues.

Respondents largely agreed with the following issues:

- It takes too long until the results can be viewed; Technology has confusing specifications with an unpredictable outcome; it is difficult to harmonize 3D imaging with strategic priorities.

Respondents largely disagreed with the following statements:

- That there would be long term conservation issues caused by 3D imaging (for example because of lightsensitive material) or through handling; intellectual Property (IP) Rights were not seen as the major problem, as most respondents were neutral or disagreed.

Respondents tended to be less worried or neutral about the fact that 3D object does not look like the real object (material, gloss, colour, geometry). This is, in fact, a confirmation that digital surrogate object looks very much like the real object to online respondents. The survey results show that heritage professionals are very open to try 3D imaging with their objects without fear of damaging the artefact.

Current barriers for adoption of 3D imaging are affected by economic issues, such as time and cost factors of equipment, and the time and cost of training provision for specialist personnel (e.g. professional photographers in the documentation department). Heritage professionals also thought that there was

- Lacking guidance about decision making for 3D imaging sensors; No common comparison standard for manufacturer-independent testing of sensors; the lack of a suitable workflow pipeline and unpredictable outcomes; finally, the unclear long-term sustainability 
of data and therefore unclear contribution to the strategic aims of the institution with valuable (possibly commercial) digital assets.

Barriers for adoption are therefore not only equipment cost, staff time and sustainability, but also a confusing and not goal oriented production pipeline.

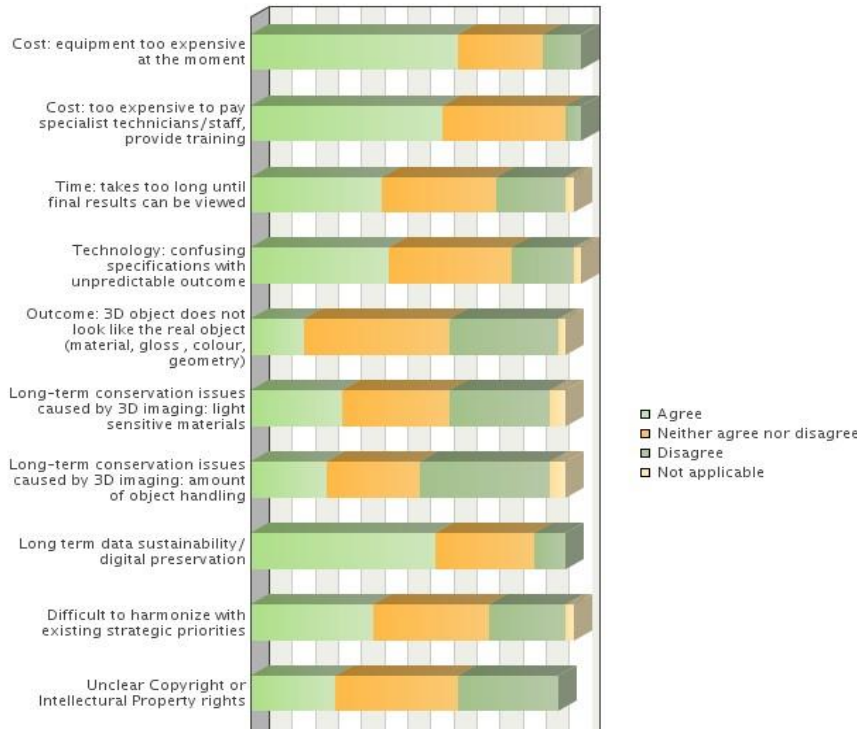

Figure $123 \mathrm{D}$ imaging requirements after a 3D imaging activity has taken place.

\section{H. The future of $3 D$ imaging in museums}

The next question enquired which technology was seen as the most promising for increased adoption by museums and cultural heritage in the next five to ten years (Question 18). Respondents very clearly agreed that high-resolution photography for condition-reporting, assessment and photography would remain the technology of choice. The 'Structure from Motion' approach with professional digital SLR cameras $(64.1 \%)$ had a future and the combination of technologies was seen to be most promising choice $(57.58 \%)$. Over half of the respondents agreed that terrestrial laser scanning $(56.1 \%)$, professional 2D photography for catalogues $(53.85 \%)$ would be staying with the cultural heritage 3D imaging activities. Other technologies which are more recently established in the cultural heritage imaging, such as PTM/RTI, 3D handheld laser scanning, 3D scanning with consumer grade sensor, 3D high-resolution scanning, were rated as promising with an agreement of over $40 \%$. Known and reliable 3D triangulation technologies, i.e. handheld 3D laser scanning were well regarded (45-55\% agreement). Other technologies, like multispectral and hyperspectral imaging and fringeprojection scanning at ca. $55 \%$ agreement of respondents for possible future use.

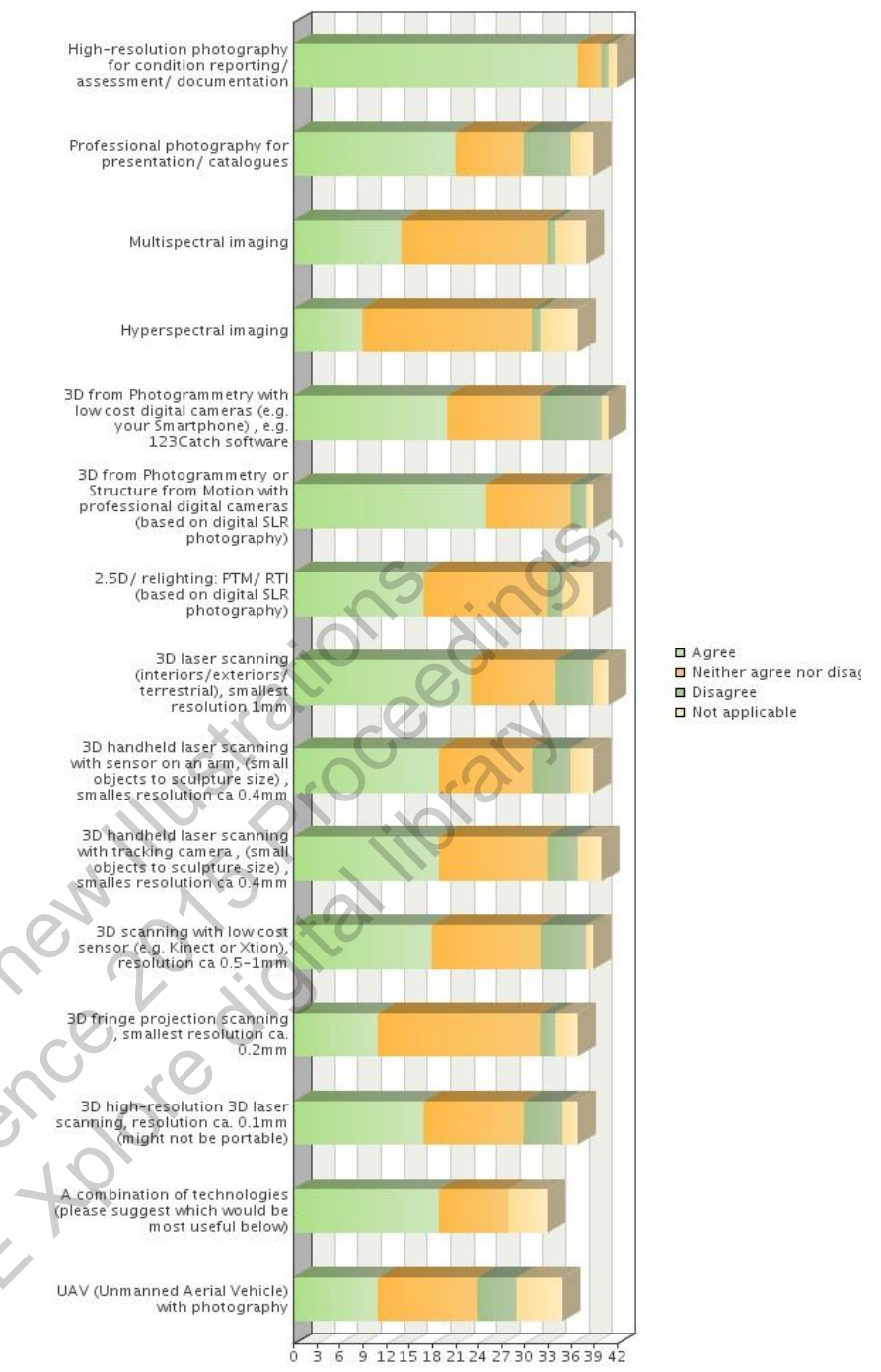

Figure 13 Which technology is most promising for the future of 3D imaging in cultural heritage? Which technology is most promising for increased take-up by museums/ cultural heritage $(\mathrm{CH})$ in the next 5-10 years

Question 19 enquired about what future development should be in the 3D imaging area. The need to further improve spatial recording was not seen as urgent by respondents. This might be because it is an issue largely solved by existing photographic metrics. Otherwise, respondents agreed strongly with most issues:

- Integrate 3D into your workflow; specialized personnel such as a 3D imaging technician/ conservator; Equipment owned by a consortium; common calibration standard such as a heritage test object; Improve spectral and tonal recording; and improve surface properties recording.

Heritage professionals were very clear that they wanted standardized data formats and long term sustainability.

Asked, what would increase the likelihood to integrate 3D recording into their workflow today (Question 21), respondents clearly agreed with three answers:

- $\quad$ Best practice guidelines for 3D imaging of objects; a solution for long term storage and sustainability of data; 3D and 2.5D images could be an asset for the institution for documentation and research. 


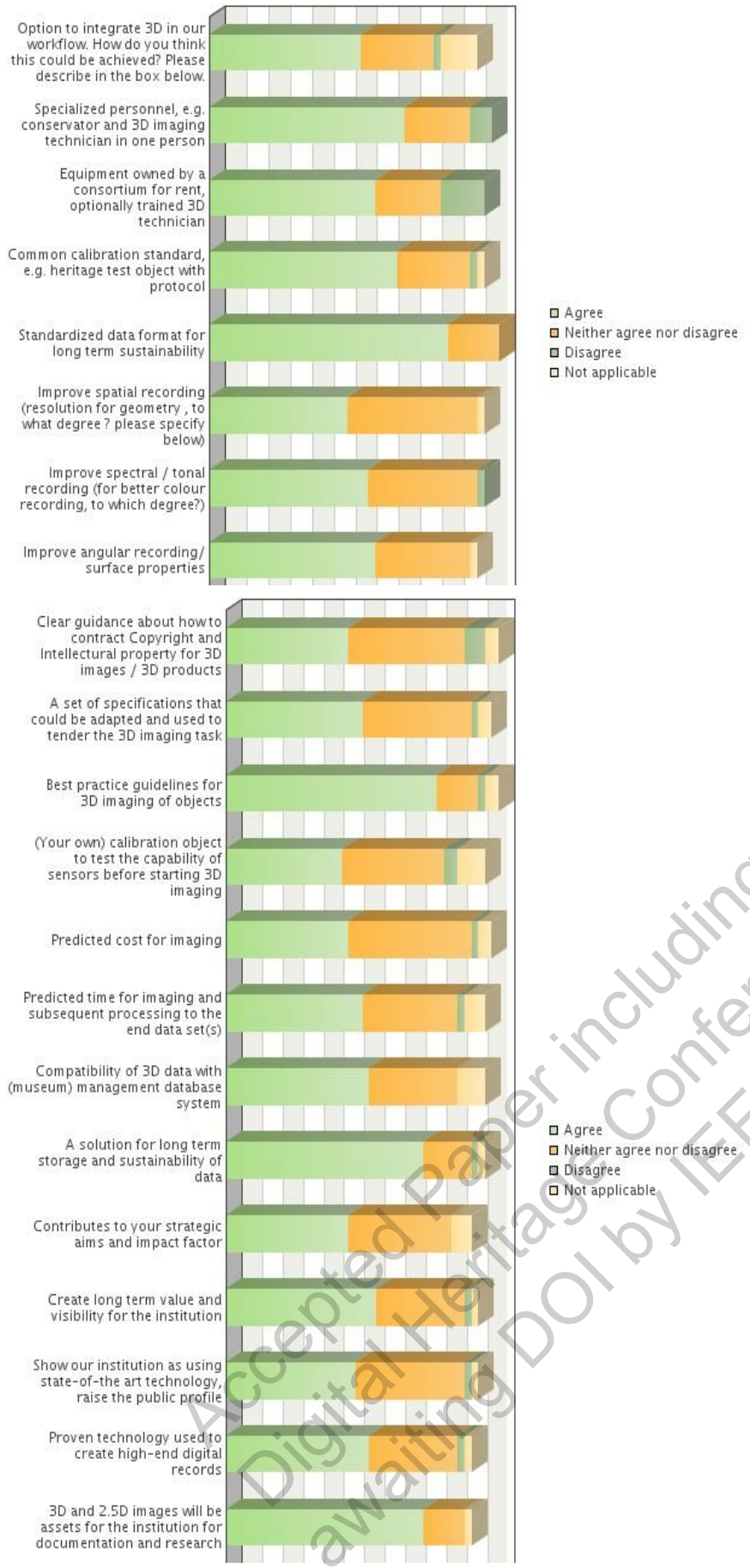

Figure 14 What future development should be in the 3D imaging area.?

\section{CONCLUSION}

Despite a number of barriers, there is a high interest in $3 \mathrm{D}$ imaging technologies across heritage institutions and the museum sector. Overall, while there were many respondents from an academic environment, the survey was able to reach out to a great diversity of professionals in heritage institutions involved in the museum work, from traditional roles (conservator, curator) to more technical roles (digital documentation technicians). There is clearly a great interest in the topic of digital 3D imaging confirmed by the large number of respondents from all fields of cultural heritage, from all over the world. The object size indicates that close-range object imaging will be able to address the most frequent object size, if the object is compatible (i.e. not transparent or shiny, flexible or black). Further investigation into the object classes that can be addressed is future work.

While there might be organisational barriers to overcome to enable the acceptance and adoption of 3D imaging in heritage institutions, the technology of non-contact optical surface recording is well suited for the production of scientific archival records. The ENUMERATE report established that of all objects, the significant percentage $(50 \%)$ of $3 \mathrm{D}$ objects held by European Museums, currently only about $0.1 \%$ of these museum artefacts are digitized in 3D [11]. Short-term investment of time, cost and training might seem daunting to heritage institutions. However, ongoing efforts to develop mass digitisation will enable long-term benefits and provide opportunities to use 3D image databases not only for scientific research but also to enable the 'public to explore collections for inspiration, learning and enjoyment' and 'to research, share and interpret information related to collections, reflecting diverse views' [12]. Museums will be a contributor to the Digital Economy and Creative industries research and development still has to go into embedding 3D digitisation campaigns into the museum workflow.

The survey is part of a recently completed doctoral research project addressing metric quantitative $3 \mathrm{D}$ image quality testing based on engineering metrology and qualitative user testing of digital surrogates on screen next to a real object with 22 interviewees [13]. As a result for the call for accurate geometric recording, a procedure for metric accuracy tests for different sensors was taken up as the subject of a detailed study with metric quantitative tests [14] [15] [16]. A graphical representation method for 3D quality indicators was generated, which can be used to match 3D sensors to both user requirements and object properties. This proposed framework, including writing a project brief, specifications and quality control, allows heritage professionals to plan fit-for-purpose 3D imaging and assess a digital 3D surrogates for analysis and research use. The 3D imaging framework methodology is transferable and will impact and benefit project planning of 3D imaging programmes in cultural heritage institutions. 


\section{REFERENCES}

[1] M. Terras, C. Ross, and V. Motyckova, "Measuring impact and use: scholarly information-seeking behaviour," in Evaluating and Measuring the Value, Use and Impact of Digital Collections, L. M. Hughes, Ed. London: Facet Publishing, 2012.

[2] 3D-Coform and D. Arnold, "D.2.1 - Initial version of 'User Requirement analysis and Functional Specifications' - Tools and Expertise for 3D Collection Formation (Public Deliverables)." Sep-2009.

[3] D. Gillespie, A. La Pensée, and M. Cooper, "User appropriate viewer for high resolution interactive engagement with 3D digital cultural artefacts," ISPRS - Int. Arch. Photogramm. Remote Sens. Spat. Inf. Sci., vol. XL-5/W2, pp. 271-276, Jul. 2013.

[4] D. Gillespie, A. La Pensée, and M. Cooper, "3D Cultural Heritage Online; In Search of a User Friendly Interactive Viewer," Int. J. Herit. Digit. Era, vol. 3, no. 1, pp. 51-68, Mar. 2014.

[5] A. Blandford, A. Adams, S. Attfield, G. Buchanan, J. Gow, S. Makri, J. Rimmer, and C. Warwick, "The PRET A Rapporter framework: Evaluating digital libraries from the perspective of information work," Inf. Process. Manag., vol. 44, no. 1, pp. 4 21, Jan. 2008.

[6] Objectplanet, Opinio. 2013.

[7] M. Hess, "Current use of 3D imaging in museums and memory institutions. User requirements for $3 \mathrm{D}$ images for analysis and research use," Mona Hess - UCL - PhD - online survey, Jun-2013. [Online]. Available: https://opinio.ucl.ac.uk/s?s=23508.

[8] MCG, "Museums Computer Group: connect, support, inspire museum tech professionals," 2014. [Online]. Available: http://museumscomputergroup.org.uk/. [Accessed: 05-Apr2014].

[9] M. Hess, "Invitation to the Online Survey by M.Hess on 24 July 2013 via JISCMail - Museum Computer Group.," Museum Computer Group, 24-Jul-2013. [Online]. Available: http://bit.ly/16aOLLO. [Accessed: 05-Apr-2014].

[10] Conservation Online and H. Walter, "Conservation DistList," 2014. [Online]. Available: http://cool.conservationus.org/byform/mailing-lists/cdl/aboutcdl.shtml. [Accessed: 05Apr-2014].

[11] N. Stroeker and R. Vogels, "ENUMERATE - Survey Report on Digitisation in European Cultural Heritage Institutions 201 4." Enumerate Thematic Network, Jan-2014.

[12] UK Museums Association, UK Museum Association - Code of Ethics. 2008.

[13] M. Hess, "A metric test object informed by user requirements for better 3D recording of cultural heritage artefacts," $\mathrm{PhD}$, University College London (UCL), London, 2015.

[14] M. Hess and S. Robson, "3D imaging for museum artefacts: a portable test object for heritage and museum documentation of small objects," in ISPRS - International Archives of the Photogrammetry, Remote Sensing and Spatial Information Sciences, Melbourne, Australia, 2012, vol. XXXIX-B5, pp. 103-108.

[15] M. Hess, S. Robson, and A. Hosseininaveh Ahmadabadian, "A contest of sensors in close range 3D imaging: performance evaluation with a new metric test object," ISPRS - Int. Arch. Photogramm. Remote Sens. Spat. Inf. Sci., vol. XL-5, pp. 277-284, Jun. 2014.

[16] M. Hess, I. Toschi, E. Nocerino, F. Menna, B. Sargeant, L. Macdonald, F. Remondion, and S. Robson, "Improving automated 3D reconstruction methods via vision metrology," in In: (Proceedings) SPIE Optical Metrology., 2015. 